\title{
Optimal Configuration of Converter for HVDC Transmission System
}

\author{
Roshan Ghosh $^{1}$, Sudip Kumar Ghorui ${ }^{2}$ \\ ${ }^{1}$ Assistant Professor, Department of Electrical Engineering, Budge Budge Institute of Technology, Kolkata, India \\ ${ }^{2}$ Assistant Professor, Department of Electrical Engineering, Budge Budge Institute of Technology, Kolkata, India
}

\begin{abstract}
A novel method is proposed for configuring a power electronics converter circuit for optimal performance in HVDC transmission system. It is configured depending upon the desired output voltage pulses. Assuming high number of pulses in output voltage optimal configuration is obtained by achieving maximum possible output voltage, minimum Peak Inverse Voltage, and by obtaining transformer utilization factor value near unity. This paper suggests an analytical way of designing the converter circuit based on certain assumptions. A mathematical model of the scheme is developed. Detailed analysis and simulation results are presented in LabVIEW 7.1 software.
\end{abstract}

Keywords: HVDC, LabVIEW, power electronics Converter, PIV, TUF

\section{Introduction}

The driving force for the development of power systems is the on-going increase of electrical power demand. High Voltage Direct Current (HVDC) system plays vital role in today's power system around the w orld and will continue to contribute more with the advent of Smart Super Grid in the future. Over the past few decades expanding power grids has proven to be both economically and environmentally desirable [1]. Presently power system operates under a high stress level which was neglected at the moment they were designed. The operating conditions of power system are being threatened form the reliability, controllability and security point of view. HVDC transmission brings a solution to have secure and improve the stability margins of power system [4]. The characteristic like having more flexibility and efficient power flow mechanism, as it provides a bidirectional power flow and is capable of controlling both active power and reactive power independently of each other, to keep stable voltage and frequency[2]. It can prevent voltage collapse by using gradual P\&Q modulation including reducing the active power to increase reactive power capability is needed. [16].

HVDC transmission resides a two basic type of converter technology. Those are classical line commutated current source converter (CSCs) where DC side polarity remain same, power flow decided by DC side voltage polarity and self-commutated voltage sourced converters (VSCs) where DC side voltage polarity will remain same, power flow direction decided by DC side current polarity [3]. Classical HVDC technology employs line commutated current source converters with thyristor valve used as a base technology for DC transmission. Where thyristors are not fully controlled switches, hence it put limitation to control mechanism used for controlled power flow [14]. Voltage source converter based transmission technology introduces flexibility in power transmission, as it uses fully controllable switches like IGBT which provides one of the efficient control mechanisms for control of power flow. Both classical and VSC-HVDC are used for the applications like long distance transmission, underground and undersea cable transmission and interconnection of asynchronous networks. [6]. Thyristor based classical HVDC mostly used for point to point large power transmission long distance over land or undersea cables [20]. It has certain disadvantage like commutation failure as thyristors can't be off immediately, and it requires $40 \sim 60 \%$ reactive power supply of the total active power transmission [17.. To have a solution IGBTs are used that can be switched off and on immediately, no commutation problem, active and reactive power control independently, no reactive power compensation required, filter requirement is less as to filter out high frequency signals from PWM. [7].

VSC -HVDC link consist of a back to back voltage sourced converters (VSCs), a common DC link, which includes a large DC capacitors and DC cables [18]. The control strategy is being designed to coordinate the active power control between two station which is realized by controlling the DC side voltage of one converter where other converter control the active power. Automatic control of power flow between stations is the result of a constant DC voltage source gives slack bus". [6]. AC voltage control and reactive power control will be switched as per the requirement. Power system operates closer to their stability limits, which may affect the damping of electromechanical oscillation and risks the system with a decreased system stability margin.

Configuration of an efficient and reliable HVDC converter is very important for the optimal operation of the HVDC transmission system [14]. It is experimentally proven that if the number of output pulses of the converter is high then the system gets much more proficient ripple free DC output and it will reduce the harmonics in AC side as well as the DC side. [9].But it is also not possible to have very large number of pulses, and then your circuit becomes very complex. In this paper HVDC converter has been configured for optimal performance of the system assuming 6 and 12 pulses. In the experimental result it is shown that specific configuration of converter circuit gives the optimal performance of the HVDC 


\section{International Journal of Science and Research (IJSR) \\ ISSN (Online): 2319-7064}

Index Copernicus Value (2013): 6.14 | Impact Factor (2014): 5.611

transmission system.

\section{Characteristics of HVDC converter}

For best possible performance in HVDC transmission system the converter must have the following characteristics:

\subsection{High pulse number (p)}

Large number of pulses will reduce the harmonics and hence filter circuit requirement will be less. So, the optimal number of pulse numbers normally the six pulse converters is very good, because the six pulses gives the desire the merits or features of converter circuit, six pulse is optimal. But at the same time, the two six pulses if shift by certain angle means 30 degree, twelve pulse can be obtained [13].

\section{$2.2 \mathrm{PIV} / \mathrm{V}_{\mathrm{do}}$ should be minimum}

Peak inverse voltage (PIV) should be as low as possible if the peak inverse voltage is less here means less costly converter valve, means this is related directly to the cost of the converter [16]. Because the converter is consisting of your valves here; for large peak inverse voltage the cost of whole circuit is going to be more. So the ratio of PIV to converter output voltage $\left(\mathrm{V}_{\mathrm{do}}\right)$ should be minimum [8].

\section{$2.3 V_{d o}$ /R.M.S Voltage should be maximum}

If any circuit which is giving more DC output voltage that is a better for same configuration. For the optimal converter design getting maximum possible output voltage is one of the major criteria [21].

\subsection{Transformer Utilization Factor (TUF) should be close to unity}

If converter is not properly configured then transformers are not utilized to their full potential [13]. Utilization factor is the best in the bridge rectifier circuit. That is why it is used very properly and in these circuits, all almost all of the applications. [22].

\section{Mathematical model}

For designing the mathematical model of the converter circuit the following assumptions are made:

- Supply to the converter is balanced 3phase supply

- All the semiconductor switches used in converter circuit are ideal switches

- Commutation overlap angle has been ignored

Leakage Reactance of the transformers are neglected

- Delay angle is assumed to be zero

Let,

$\mathrm{P}$ is desired number of output voltage pulses of the converter

$\mathrm{q}$ is number of valves in a commutating group

$r$ is number of parallel valves of converter circuit

$\mathrm{s}$ is number of parallel valves of converter circuit

Em is the Peak voltage
Output voltage of three pulse converter

$$
\begin{aligned}
& \mathrm{V}_{\mathrm{do}}=\frac{3}{2 \Pi} \int_{-\Pi / 3}^{\Pi / 3} E m \operatorname{Cos} \omega t d(\omega t) \\
& \text { so } \mathrm{V}_{\mathrm{do}}=\frac{3 \sqrt{3}}{2 \Pi}
\end{aligned}
$$

now this equation [1] can be generalized by-

$$
\mathrm{V}_{\mathrm{do}}=\frac{q \operatorname{EEmsin}(\Pi / q)}{2 \Pi}
$$

Now

$$
V_{\mathrm{do}} / \text { r.m.svoltage }=\frac{\sqrt{2} q \sin (\Pi / q)}{2 \Pi I}
$$

When $\mathrm{q}$ is even then

$$
\operatorname{PIV} / V_{\text {do }}=\frac{2 \Pi}{q \sin (\Pi / q)}
$$

When $\mathrm{q}$ is odd then

$$
\mathrm{PIV} / V_{d o}=\frac{\Pi}{q \sin (\Pi / 2 q)}
$$

Transformer Utilization Factor can be expressed as

$$
T U F=\frac{\Pi}{\sqrt{2 q} \sin (\Pi / q)}
$$

Using the above mathematical equations with different combinations of $\mathrm{q}, \mathrm{r}$ and $\mathrm{s}$ for a particular no of pulses optimal performing condition of a converter can be identified which is shown in result. [6]

\section{Result and Discussions}

Optimal configuration of converter is sized assuming the output voltage pulses of converter is 6 pulses.(i.e. $p=6$ ) and 12 pulses (i.e. $\mathrm{p}=12$ ) is obtained by using the equation [2],[3],[4],[5].

Table 1: Optimal performance of 6 pulse converter

\begin{tabular}{|c|c|c|c|c|c|c|}
\hline $\begin{array}{c}S L \\
\text { No }\end{array}$ & $q$ & $r$ & $s$ & $P I V / V_{d o}$ & $V_{d d} / r . m . s$ voltage & TUF \\
\hline 1 & 2 & 1 & 3 & 1.0472 & 2.70092 & 1.5708 \\
\hline 2 & 2 & 3 & 1 & 3.1415 & 0.900308 & 1.5708 \\
\hline 3 & 3 & $\mathbf{1}$ & 2 & $\mathbf{1 . 2 0 9 2}$ & 3.11876 & $\mathbf{1 . 4 8 0 9 8}$ \\
\hline 4 & 3 & 2 & 1 & 2.4184 & 1.55938 & 1.48098 \\
\hline 5 & 6 & 1 & 1 & 2.0944 & 5.40185 & 1.81382 \\
\hline
\end{tabular}




\section{International Journal of Science and Research (IJSR) \\ ISSN (Online): 2319-7064}

Index Copernicus Value (2013): 6.14 | Impact Factor (2014): 5.611

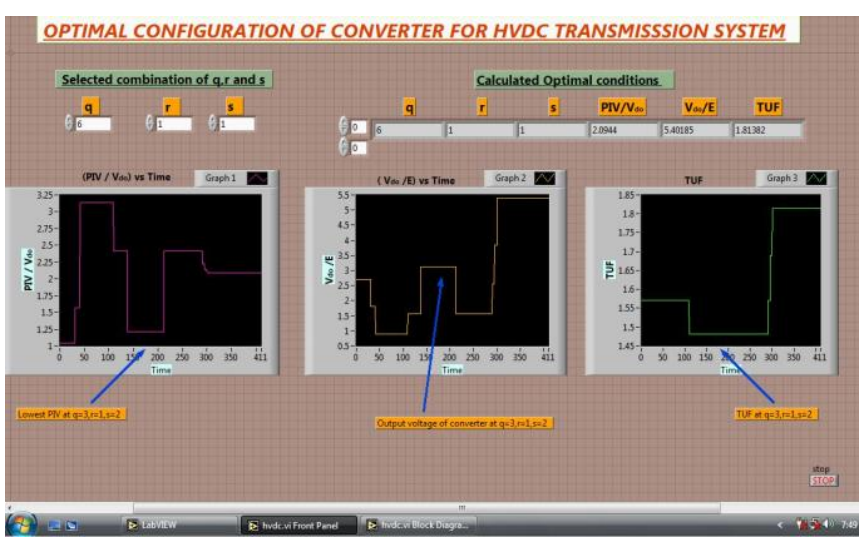

(a)

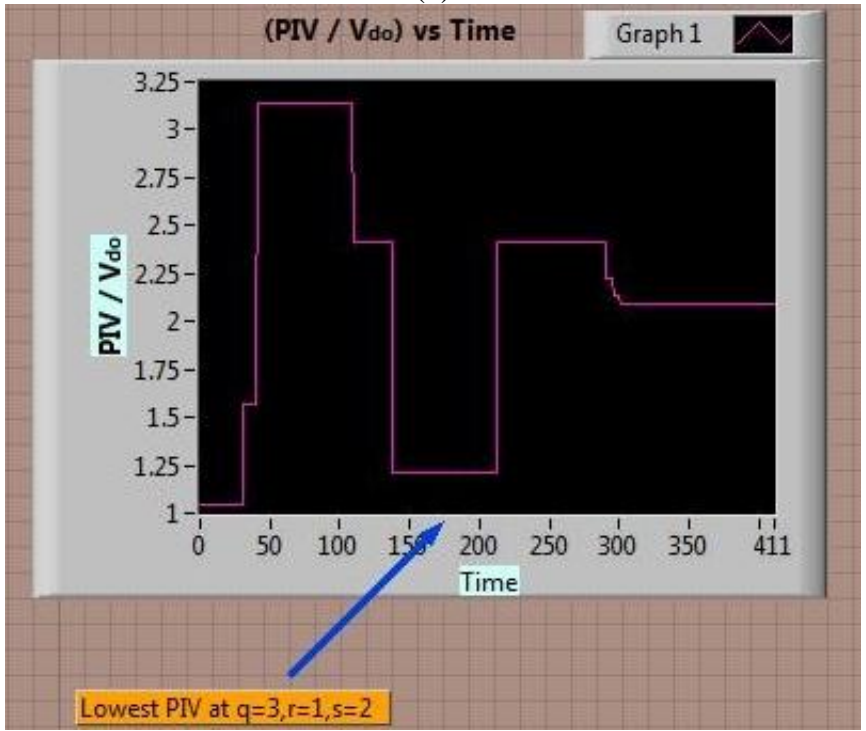

(b)

Figure 1: Front panel view of LabVIEW program for Identification of optimal 6 pulse converter configuration (a)variation of PIV, $\mathrm{V}_{\text {od }}, \mathrm{TUF}$ with different combination of q,r,s with time ,(b)PIV voltage variation, (c)Converter output voltage variation, (d)TUF variation

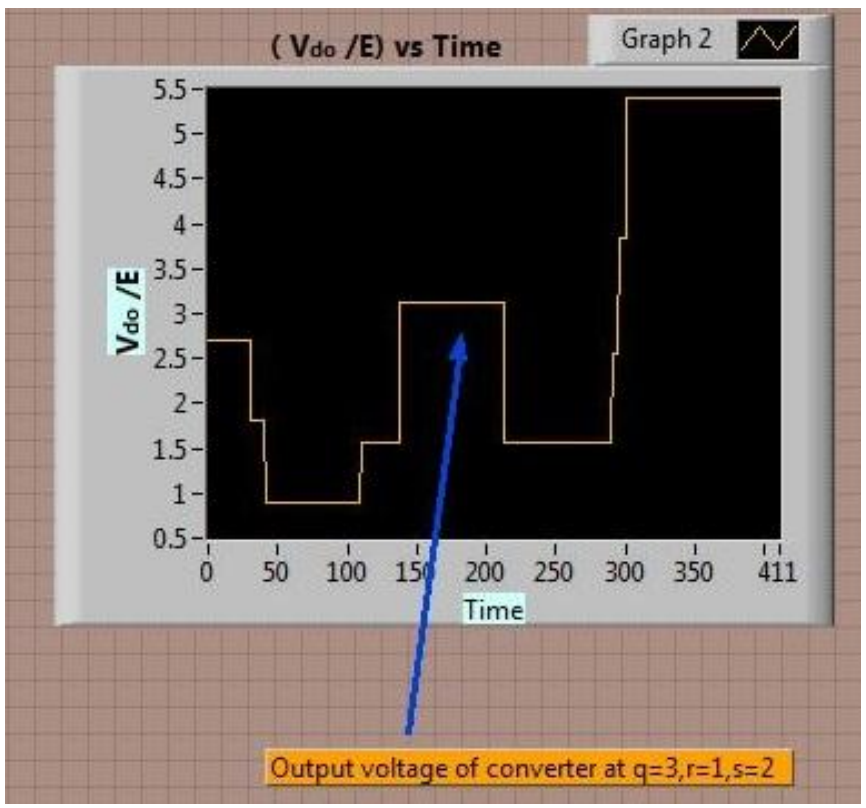

(c)

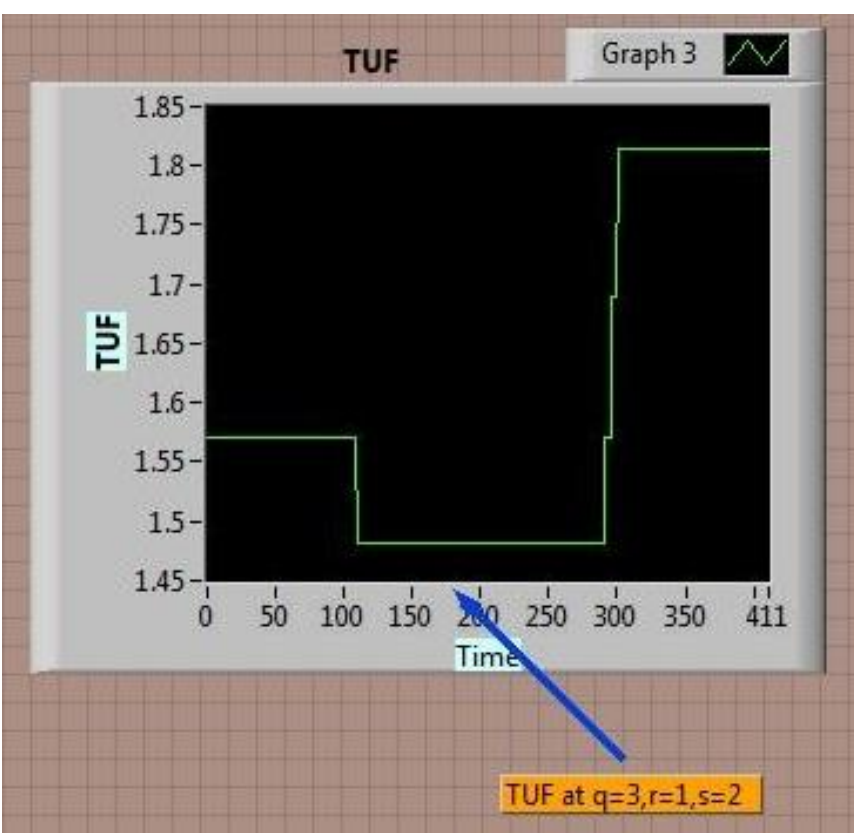

(d)

A programming has been developed using the mathematical model for identification of optimal configuration HVDC converter in LabVIEW 7.1 software [29]. Table 1 shows the result for different combination of q,r and $s$ when no of pulse $\mathrm{p}$ is taken as 6.It is observed that when the combination is $\mathrm{q}=3, \mathrm{r}=1$ and $\mathrm{s}=2$ then the converter satisfies all the criteria for optimal performance. The highlighted row ( $3^{\text {rd }}$ row) of Table 1 shows PIV/ $\mathrm{V}_{\text {od }}$ is less, $\mathrm{V}_{\text {od }} / \mathrm{r}$.m.s voltage also gives increased output voltage and TUF is also nearly unity with this combination. Figure 1 shows graphical display of programming output and detects optimal converter circuit configuration for best performance on HVDC transmission system.

Table 2: Optimal performance of 12 pulse converter

\begin{tabular}{|c|c|c|c|c|c|c|}
\hline $\begin{array}{c}S L \\
\text { No }\end{array}$ & $q$ & $r$ & $s$ & $P I V / V_{d o}$ & $V_{d o} /$ r.m.s voltage & $T U F$ \\
\hline 1 & 12 & 1 & 1 & 2.02303 & 20.8711 & 2.47772 \\
\hline 2 & 6 & 1 & 2 & 1.0472 & 10.8037 & 1.81382 \\
\hline 3 & 6 & 2 & 1 & 2.0944 & 5.40185 & 1.81382 \\
\hline 4 & 3 & 4 & 1 & 2.4184 & 1.55983 & 1.48098 \\
\hline $\mathbf{5}$ & $\mathbf{3}$ & $\mathbf{1}$ & $\mathbf{4}$ & $\mathbf{0 . 6 0 4 6}$ & $\mathbf{6 . 2 3 7 5 1}$ & $\mathbf{1 . 4 8 0 9 8}$ \\
\hline 6 & 2 & 1 & 6 & 0.523599 & 5.40185 & 1.57081 \\
\hline 7 & 3 & 2 & 2 & 1.2092 & 3.11876 & 1.48098 \\
\hline
\end{tabular}

OPTIMAL CONFIGURATION OF CONVERTER FOR HVDC TRANSMISSSION SYSTEM Selected combination of g,r ands

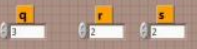
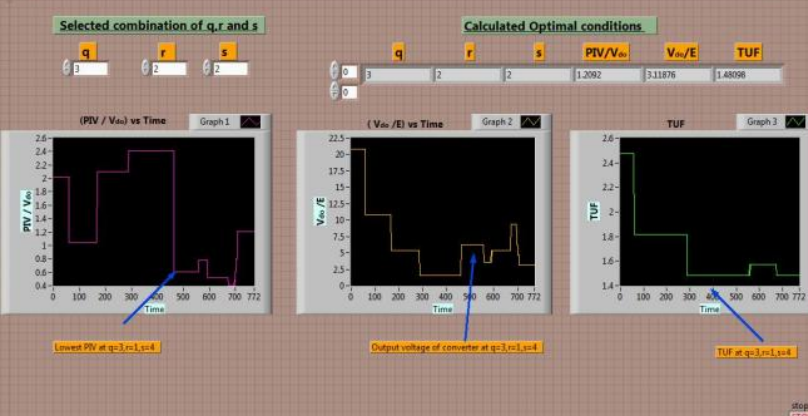

$\infty$

(a) 


\section{International Journal of Science and Research (IJSR) \\ ISSN (Online): 2319-7064}

Index Copernicus Value (2013): 6.14 | Impact Factor (2014): 5.611

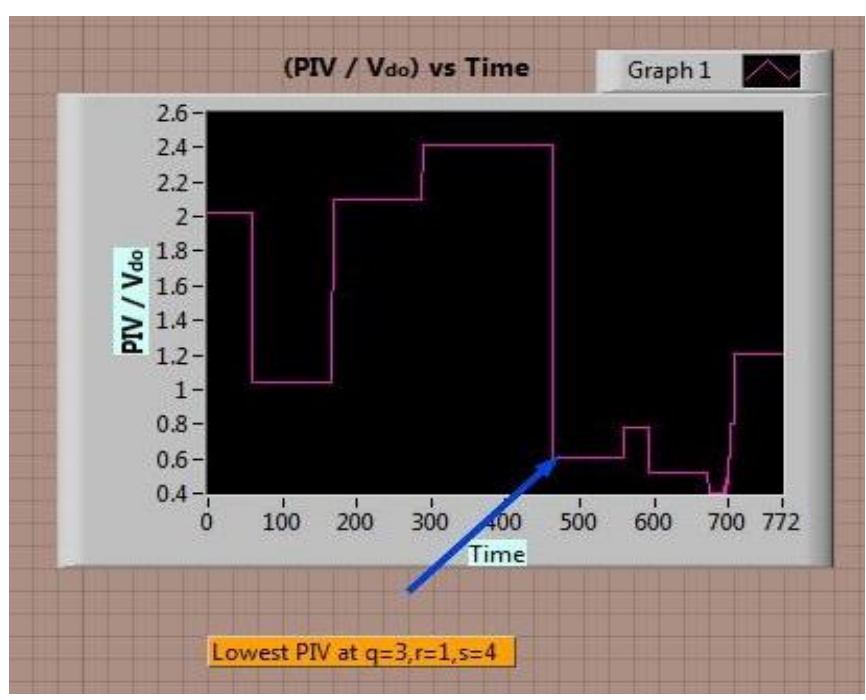

(b)

Figure 2: Front panel view of LabVIEW program for Identification of optimal 12 pulse converter configuration (a)variation of PIV, $\mathrm{V}_{\text {od }}, \mathrm{TUF}$ with different combination of q,r,s with time ,(b)PIV voltage variation, (c)Converter output voltage variation, (d)TUF variation

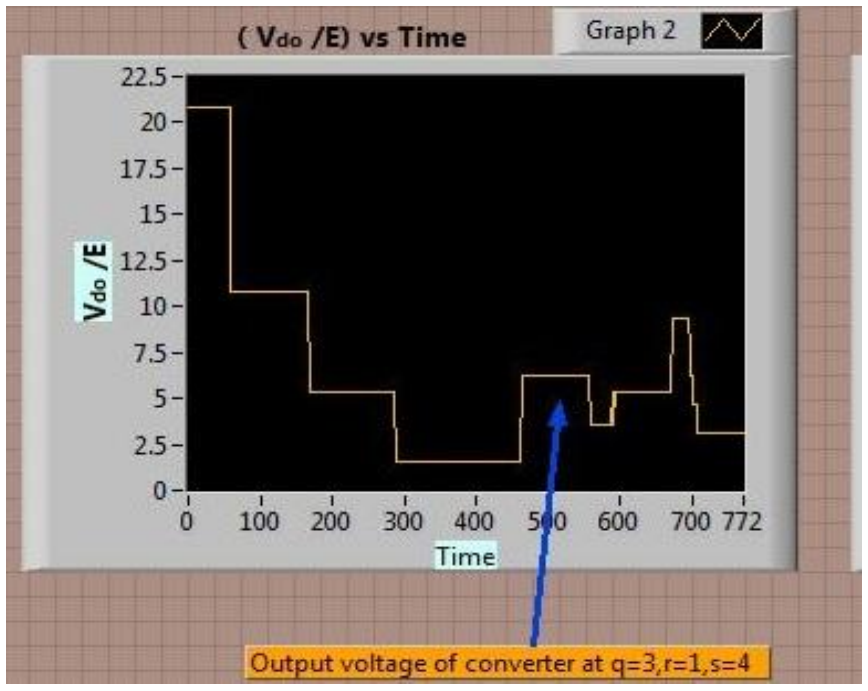

(c)

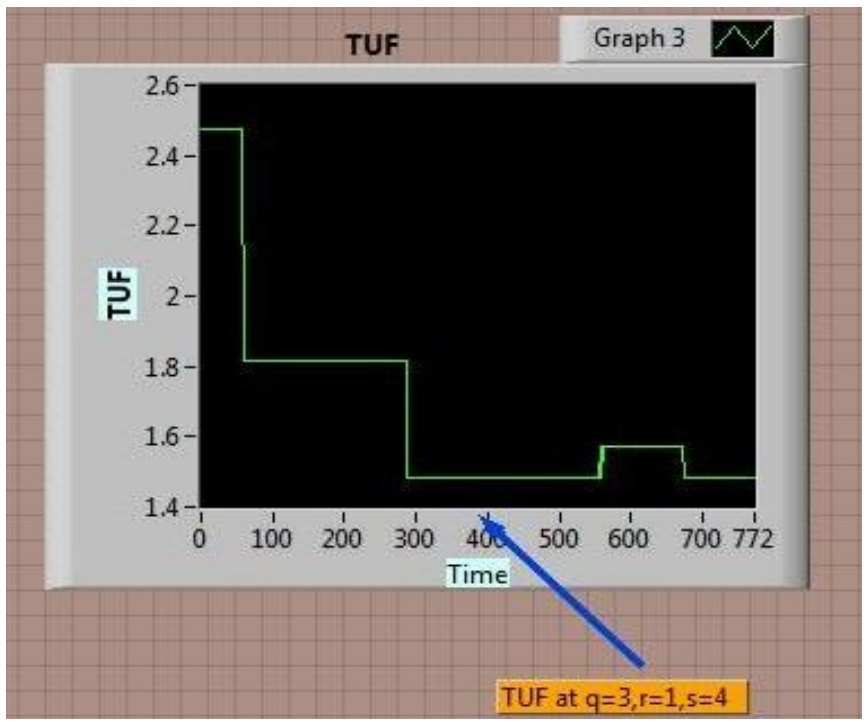

(d)
The programming has been also tested on 12 pulse converter and results have been tabulated on Table 2; the highlighted row $\left(5^{\text {th }}\right.$ row) of Table 2 shows optimal performance [33.. In the graph figure 2 shows when the combination of the converter circuit has the following values $\mathrm{q}=3, \mathrm{r}=1$ and $\mathrm{s}=4$ then Peak Inverse Voltage ratings is lowered significantly so converter valves don't have to block high PIV and converter cost will be less and in this configuration converter output voltage also increased and TUF is nearly unity which means transformer can also be utilized efficiently.

But if any other values of q,r,s are taken converter do not give desired performance for example if $\mathrm{q}=12, \mathrm{r}=1, \mathrm{~s}=1$ then converter output is very high but PIV is also excessively high which increases the converter valve rating and thus cost of the converter increases. In this condition TUF is also well away from unity.

\section{Conclusions}

This paper suggests the configuration of a cost effective reliable HVDC converters. This optimal configured converted not only improves the HVDC transmission system performance but it also improves the efficiency of transformers used at the AC supply end. As the HVDC system has become popular due to the requirement of power transmission over long distance so this optimal configuration technique of converter can be used for better performance. This converter can be used in multilink HVDC system, Hybrid AC/DC system, Micro grid systems, Wind power generating station.

\section{References}

[1] Beccuti, G. Papafotiou, G. Harnefors, L. (2014). Multivariable Optimal Control of HVDC Transmission Links With Network Parameter Estimation for Weak Grids. The International Journal of Control Systems Technology, IEEE Transactions, Vol. 22, 676 - 689.

[2] R. Kumar, T. Leibfried, 2005, Analytical Modelling of HVDC Transmission System Converter using Matlab/Simulink, IEEE Technical conference on Industrial and Commercial Power Systems, pp. 140146.

[3] Gum Tae Son; Hee-Jin Lee; Tae Sik Nam; Yong-Ho Chung; Uk-Hwa Lee; Seung-Taek Baek; Kyeon Hur; Jung-Wook Park, "Design and Control of a Modular Multilevel HVDC Converter With Redundant Power Modules for Noninterruptible Energy Transfer" Power Delivery, IEEE Transactions on, vol.27, no.3, pp.1611,1619, July 2012.

[4] R Forest, G Heyner, KW Kanngeisser, and H Waldmann, "Multiterminal Operation of HVDC Converter Stations",IEEE Trans. Power Appartus and Systems, vol. 88, no. 7, 1969, pages 1042-1052.

[5] Y. Jiang-Hafner, H. Duchen, M. Karlsson, L. Ronstrom, B. Abrahamsson, HVDC with Voltage Source Converters - A Powerful Standby Black Start Facility”, presented at the IEEE PES T\&D Conference in Chicago, USA, April 21-24, 2008. 


\section{International Journal of Science and Research (IJSR) \\ ISSN (Online): 2319-7064}

Index Copernicus Value (2013): 6.14 | Impact Factor (2014): 5.611

[6] V. Blasko and V. Kaura. (1997). A new mathematical model and control of a three-phase AC-DC voltage source converter, IEEE Transactions on Power Electronics, Vol. 12, 116-123.

[7] Nakajima, Tatsuhito, and Shoichi Irokawa, "A Control System for HVDC Transmission by Voltage Sourced Converters",IEEE Power Engineering Society Summer Meeting, 1999.

[8] O'Reilly, J. Wood, A.R. Osauskas, C.M. (2003). Frequency domain based control design for an HVDC converter connected to a weak AC network. IEEE Transactions on Power Delivery, Vol. 18, 1028 - 1033.

[9] Jun Liang, Tianjun Jing, O Gomis-Bellmunt, J Ekanayake and N Jenkins, Đperation and Control of Multiterminal HVDC Transmission for Offshore Windfarms", IEEE Trans. Power Delivery, vol. 26, issue 4, 2011, pages 2596-2604.

[10] WF Long, J Reeve, JR McNichol, MS Holland, JP Taisne, J LeMay, and DJ Lorden, "Application Aspects of Multiterminal DC Power Transmission",IEEE Trans. Power Delivery, vol. 5, no. 4, 1990, pages 2084-2098.

[11] Rohner, S.; Bernet, S.; Hiller, M.; Sommer, R., "Modulation, Losses, and Semiconductor Requirements of Modular Multilevel Converters," Industrial Electronics, IEEE Transactions on , vol.57, no.8, pp.2633,2642, Aug. 2010.

[12] F Nozari, CE Grund, and RL Haut, "Current Order Coordination in Multiterminal DC Systems",IEEE Trans. Power Appartus and Systems, vol. 100, no. 11, 1981, pages 4628-4635.

[13] S. Allebrod, R. Hamerski, R. Marquadt, New Transformerless, Scalable Modular Multilevel Converters for HVDC Transmisson", IEEE Power Electronics Specialists Conf., Rhodes-Greece, June 2008, pp. 174-179.

[14] L. Zhang, L. Dofnas, 2002, A Novel Method to Mitigate Commutation Failures in HVDC Systems, IEEE International Conference on power system technology, vol. 1, pp. 51-56.

[15] O Gomis-Bellmunt, A Egea-Alvarez, A Junyent-Ferre, Jun Liang, J Ekanayake and N Jenkins, Multiterminal HVDC-VSC for Offshore Wind Power Integration", IEEE Power and Energy Society General Meeting, 2011.

[16] J Reeve, IA Rose, and J Carr, Eentral Computer Controller for Multiterminal HVDC transmission systems", IEEE Trans. Power Apparatus \&Systems, vol. 96, no. 3, 1977, pages 934-944.

[17] C Meyer, M Kowal, and RD Doncker, "Circuit Breaker Concepts for Future High-Power DC-Applications", IEEE Industry Applications Conference, vol. 2, 2005, pages 860-866.

[18] C Du, A Agneholm and G Olsson, Comparison of Different Frequency Controllers for a VSC-HVDC Supplied System", IEEE Trans. Power Delivery, vol. 23, no. 4, 2008, pages 2224-2232.

[19] F Nozari, CE Grund, and RL Haut, "Current Order Coordination in Multiterminal DC Systems", IEEE Trans. Power Appartus and Systems, vol. 100, no. 11, 1981, pages 4628-4635.

[20] Mohamed Ayari, Mohamed Moez Belhaouane, Naceur Benhadj raiek, Xavier Guillaud. (2013). Optimal
Control Design for VSC-HVDC Systems. IEEE International Conference on Electrical Engineering and Software Applications (ICEESA), (pp. 1-6). Hammamet.

[21] Ferreira, J.A., "The Multilevel Modular DC Converter, "Power Electronics, IEEE Transactions on, vol.28, no.10, pp.4460,4465, Oct. 2013.

[22] D. Jovcic, Bidirectional, high-power DC transformer", IEEE Transactions on Power Delivery, 24, (4), pp. 2276-2283, 2009.

[23] Abu-Rub, H., Holtz, J., Rodriguez, J., Baoming, G.: Medium-voltage multilevel converters - state of the art, challenges, and requirements in industrial applications', IEEE Trans. Ind. Electron., 2010, 57, (8), pp. 2581-2596.

[24] O.B Nayak , A. M. Gole, 1994,"Dynamic Performanceof Static and Synchronous Compensators at an HVDC Inverter Bus in a Very Weak AC System", IEEE Transactions on Power Delivery, vol. 9, no. 3, pp. 1350-1358.

[25] G. Bhuvaneswari, B. C. Mahanta, 2009, Analysis of Converter Transformer Failure in HVDC Systems and Possible Solutions, IEEE Transactions on Power Delivery, vol. 24, no. 2, pp. 814-821.

[26] R. H. Lasseter, F. W. Kelley, C. B. Lindh, 1977, DC Filter Design Methods for HVDC Systems, IEEE Transactions on Power Apparatus and Systems, vol. 96, no. 2, pp. $571-578$.

[27] Yinglin Xue, Zheng $\mathrm{Xu}$, Member, IEEE, and QingruiTu, student Member,IEEE Modulation and Control for a New Hybrid Cascaded Multilevel Converter With DC Blocking Capability" IEEE transaction on power delivery, VOL. 27, NO.4, October 2012.

[28] Bendre and G. Venkataramanan, Neutral current ripple minimization in a three-level rectifier," IEEE Trans. Ind. Appl., vol. 42, no. 2, pp. 582-590, Mar./Apr. 2006.

[29] Jing Chen; Tianhao Tang, "Power quality analysis based on LABVIEW for current power generation system," Power Electronics, Electrical Drives, Automation and Motion (SPEEDAM), 2012 International Symposium on , vol., no., pp.865,870, 20-22 June 2012.

[30] Chi ChungKo,Senimor Member. IEEE, Ben M.Chen,shanyao Hu,Vikram Ramakrishnan, Chang Dong Cheng,Yuan Zhuang,and Jianping Chen.A WebBased Virtual Laboratory on a Frequency Modulation Expriment, IEEE2001, 295-303.

[31] Laskar, Shahedul Haque; Muhammad, Mohibullah" Power Quality Monitoring by Virtual Instrumentation using LabVIEW," Universities' Power Engineering Conference (UPEC), Proceedings of 2011 46th International, vol., no., pp.1,6, 5-8 Sept. 2011.

[32] Jin-Hong Jeon; Jong-Yul Kim; Hak-Man Kim; Seul-Ki Kim; Changhee Cho; Jang-Mok Kim; Jong-Bo Ahn; Keo-Yamg Nam, Đevelopment of Hardware In-theLoop Simulation System for Testing Operation and Control Functions of Microgrid," Power Electronics, IEEE Transactions on, vol.25, no.12, pp.2919,2929, Dec. 2010.

[33] Sanghun Choi; Saeedifard, M., An Educational Laboratory for Digital Control and Rapid Prototyping

\section{Volume 5 Issue 3, March 2016}


of Power Electronic Circuits," Education, IEEE Transactions on, vol.55, no.2, pp.263, 270, May 2012.

[34] Jimenez-Martinez, J.M.; Soto, F.; De Jodar, E.Villarejo, J.A.; RocaDorda, J., A New Approach for Teaching Power Electronics Converter Experiments," Education, IEEE Transactions on, vol.48, no.3, pp.513, 519, Aug. 2005.

[35] M.Usama Surdar, Synchronous generator simulation using LabVIEW", Journal of world academic of science, engineering and technology, vol.39, pp.392400, 2008.

\section{Author Profile}

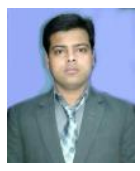

Roshan Ghosh is Assistant professor, Department of Electrical Engineering, Budge Budge Institute of technology. He obtained B-Tech (Electrical Engineering) in 2008 and M-Tech Gold Medalist (Electrical Engineering), in 2012. He has 3 years teaching experience and 2 years of industrial experience. His research interests include power electronics and electric drives, Non-conventional energy sources.

Sudip Kumar Ghorui is Assistant professor, Department of Electrical Engineering, Budge Budge Institute of technology. He obtained B-Tech (Electrical Engineering) in 2011 and M-Tech (Power System) in 2013. He has 3 years teaching experience. His research interests include power system operation, optimization, neural networks and fuzzy logic. 